\title{
Pembangunan Sistem Customer Relationship Management (CRM) menggunakan Metode Asosiasi Algoritma Apriori
}

\author{
Risma Restu Ramadina ${ }^{1 *}$, Tacbir Hendro Pudjiantoro ${ }^{2}$, Irma Santikarama ${ }^{3}$ \\ 1,2,3 Jurusan Informatika, Fakultas Sains dan Informatika, Universitas Jenderal Achmad Yani \\ Jl.Terusan Jend.Sudirman, Cibeber, Kec.Cimahi Selatan, Kota Cimahi, Jawa Barat 40531. \\ "Email: resturisma18@gmail.com
}

\begin{abstract}
Abstrak
Butik SR Fashion Store merupakan perusahaan fashion yang terletak di Kota Cimahi. Perusahaan fashion saat ini sudah banyak pesaing dimana-mana khususnya di daerah Kota Cimahi. Butik SR Fashion Store saat ini memiliki target yaitu meningkatkan jumlah pelanggan serta mempertahankan pelanggan lama. Namun karena Butik SR Fashion Store mempunyai permasalahan yaitu penyampaian dan menentukan rekomendasi masih dilakukan secara langsung ditempat, sehingga mengakibatkan ketidaknyamanan bagi pelanggan apabila rekomendasi yang ditawarkan tidak sesuai dengan selera pelanggan tersebut, karena pelayanan yang diberikan oleh pihak butik belum maksimal menyebabkan loyalitas pelanggan semakin menurun. Solusi mengatasi permasalahan tersebut harus dibuatnya Sistem Customer Relationship Management (CRM) yang dapat dikelola oleh pihak butik selain itu sistem yang akan dibangun juga dapat diakses oleh pelanggan. Sistem yang dibangun akan memberikan rekomendasi secara sistem berdasarkan histori transaksi pelanggan. Untuk memberikan rekomendasi secara sistem dengan menerapkan metode asosiasi menggunakan algoritma apriori, rekomendasi tersebut diterima oleh pelanggan member melalui pesan email. Dengan melihat histori transaksi pelanggan minimal telah melakukan transaksi lebih dari lima kali maka rekomendasi tersebut secara otomatis akan dikirim ke pelanggan member. Penerapan metode asosiasi menggunakan algoritma apriori ini menunjukan keberhasilan untuk menentukan rekomendasi produk berdasarkan histori transaksi, dengan mengambil 5 sample produk dan 7 histori transaksi dalam satu member menghasilkan 2 rule rekomendasi dengan nilai support 42,8\% dan confidence $75 \%$. Pengujian yang dilakukan yaitu menggunakan pengujian Black Box dan User Acceptence Test (UAT). Hasil dari pengujian black box yaitu fungsi yang ada di dalam sistem 100\% sudah sesuai dan untuk pengujian UAT menghasilkan 98\% penilaian kepuasan user terhadap sistem yang dibangun.
\end{abstract}

Kata kunci: pelanggan, rekomendasi, transaksi

\section{PENDAHULUAN}

Butik SR Fashion Store merupakan salah satu butik di Cimahi Jawa Barat yang didirikan pada tahun 2015. Berlokasi di Kota Cimahi tepatnya di Jl.Lurah No.82, Karangmekar, Kec.Cimahi Tengah. Butik SR Fashion Store menyediakan berbagai macam produk fashion terutama pakaian, baik pakaian wanita maupun pria dengan harga terjangkau, kualitas yang baik, serta memiliki fashion yang sangat modern.

Semakin ketatnya persaingan dan tingginya tuntutan pelanggan terhadap tingkat layanan perusahaan maka perusahaan berlomba-lomba menyediakan koleksi, penawaran dan pelayanan terbaiknya bagi pelanggan dengan memberikan rekomendasi produk yang dijual, agar tidak terjadinya tingkat penurunan pada perusahaan tersebut maka perusahaan harus mempunyai strategi agar dapat mencapai tujuan yang diinginkan (Denniswara, 2018) .

Strategi yang tepat yaitu membuat sistem customer relationship management untuk perusahaan tersebut. CRM merupakan proses atau strategi yang diterapkan perusahaan menjadi satu kesatuan yang digunakan untuk melakukan interaksi dengan pelanggan dan juga untuk menelusuri informasi pelanggan (Soltani and Navimipour, 2016). CRM mempunyai beberapa tahapan diantaranya yaitu mendapatkan pelanggan baru (acquire) mempertahankan pelanggan (enhance) dan meningkatkan loyalitas pelanggan (retain) (Faisal, Wina, 2017).

Proses penawaran rekomendasi produk masih dilakukan secara langsung ditempat yaitu kepada pelanggan. Hal tersebut kemungkinan besar tidak sesuai dengan apa yang diinginkan oleh pelanggan karena bagian pelayanan butik 
tidak mengetahui produk apa saja yang biasa dibeli oleh pelanggan dan memberikan ketidak nyamanan pelanggan saat memilih produk secara langsung di dalam toko tersebut. Hal tersebut dapat menyebabkan loyalitas pelanggan semakin menurun serta mengakibatkan penurunan pendapatan bagi perusahaan.

Terdapat metode asosiasi Menggunakan apriori untuk menentukan rekomendasi produk melalui sistem berdasarkan hasil transaksi yang dilakukan oleh pelanggan.

Metode asosiasi merupakan metode yang menemukan suatu kombinasi item yang muncul secara bersamaan. Metode asosiasi dapat digunakan untuk memberikan rekomendasi produk secara otomatis berdasarkan histori transaksi pembeli yang sudah tersimpan di dalam database (Listriani, Setyaningrum and Eka, 2018) .

Algoritma apriori merupakan salah satu algoritma klasik data mining. Algoritma apriori digunakan agar komputer dapat mempelajari aturan asosiasi, mencari pola hubungan antar satu atau lebih item dalam suatu dataset (Wijaya, 2017). Perhitungan metode asosiasi menggunakan algoritma apriori memiliki dua tahapan aturan asosiasi yaitu (Listriani, Setyaningrum and Eka, 2018) :

a. Analisis pola frekuensi tinggi

Tahap ini mencari kombinasi item yang memenuhi syarat minimum dari nilai support dalam database. Nilai support (penunjang) yaitu persentase item atau kombinasi item yang ada pada database.

b. Pembentukan aturan asosiatif

Setelah semua pola frekuensi tinggi ditemukan, maka dicari aturan asosiatif yang memenuhi syarat minimum untuk confidence dengan menghitung confidence aturan asosiatif "Jika A maka B" = (A $\square \mathrm{B})$. Dalam penelitian ini penulis memaparkan beberapa penelitian terdahulu yang menjadi acuan referensi dari penelitian yang dibuat yaitu memberikan rekomendasi produk menggunakan metode asosiasi menggunakan algoritma arpriori diantaranya yaitu : sistem rekomendasi produk online store menggunakan metode apriori, dengan menerapkan algoritma apriori sistem memberikan rekomendasi produk kepada pelanggan Online Store berdasarkan nilai confidence kombinasi produk yang dibeli pada periode waktu tertentu (Fatoni, Utami and Wibowo, 2018), implementasi metode aturan asosiasi menggunakan algoritma apriori pada data transaksi penjualan di warung special sambal, dengan menggunakan aplikasi ini pihak manajerial maupun pengelola di restoran Waroeng SS dapat mengetahui keterkaitan antar menu yang dipesan secara bersamaan (Sophia and Yuniar, 2017), implementasi data mining menentukan rekomendasi penempatan buku berdasarkan pola peminjaman dengan menggunakan association rule, dengan menggunakan metode association rule maka Dalam menemukan kombinasi 2225 data peminjaman buku perpustakaan dapat menemukan pola keterkaitan peminjaman dengan dengan minimum support 0.01 dan confidence 0.01 .(Nawawi, 2019)

Dari permasalahan tersebut tujuan yang ingin dicapai pada penlitian ini yaitu membangun Sistem Customer Relationship Management (CRM) yang dapat mengelola promosi produk serta memberikan rekomendasi produk dengan menerapkan metode asosiasi menggunakan algoritma apriori sesuai dengan histori transaksi yang ada pada database transaksi. Ada pun manfaat yang diharapkan dengan adanya sistem customer relationship management (CRM) yaitu memberikan kemudahan kepada pihak butik untuk memberikan rekomendasi produk dan promosi produk, hal tersebut dapat mempertahankan dan meningkatkan loyalitas pelanggan.

\section{METODE PENELITIAN}

Metode penelitian berisi langah-langkah yang akan dilakukan dalam pembangunan sistem customer relationship management (CRM) pada Butik SR Fashion Store, yang terdiri dari pengumpulan data dan metode menentukan rekomendasi produk.

\subsection{Metode Pengumpulan Data}

Pengumpulan data merupakan proses untuk mendapatkan data yang berguna untuk penelitian. Metode yang digunakan dalam pengumpulan data yaitu :

a. Observasi

Metode ini melakukan pengamatan dan pencatatan mengenai apa saja yang ada pada Butik SR Fashion Store saat ini, baik dari sistem yang digunakan maupun kegiatan yang mencakup proses bisnis dala pengelolaan data pelanggan pada Butik SR 
Fashion Store. dengan menawarkan beberapa produk terbaru Wawancara

Metode ini merupakan proses tatap muka secara langsung dengan salah satu pihak dari Butik SR Fasion Store yang bertanggung jawab atas pelayanan, pelanggan, maupun dengan pihak-pihak lain yang terlibat dengan proses layanan pelanggan untuk memperoleh informasi secara langsung disertai dengan adanya data yang akurat.

\subsection{Menentukan Rekomendasi Produk}

Metode asosiasi menggunakan algoritma apriori digunakan untuk memberikan rekomendasi produk berdasarkan histori transaksi yang sudah dilakukan oleh pelanggan. Aturan asosiasi terbagi menjadi dua tahap yaitu : a. Analisis Pola Frekuensi Tinggi

Tahap ini mencari kombinasi item yang memenuhi syarat minimum dari nilai support dalam database. Nilai support (penunjang) yaitu persentase item atau kombinasi item yang ada pada database. Nilai support sebuah item diperoleh dengan rumus berikut :

Jika nilai support 1 item :

Support (A) = Jumlah Transaksi mengandung A Jumlah Transaksi

Jika nilai support 2 item :

Support $(\mathrm{A} \cap \mathrm{B})=\underline{\text { Jumlah Transaksi A dan B }}$ Jumlah Transaksi

b. Pembntukan Aturan Asosiatif

Setelah semua pola frekuensi tinggi ditemukan, maka dicari aturan asosiatif yang memenuhi syarat minimum untuk confidence dengan menghitung confidence aturan asosiatif "Jika A maka B" $=(\mathrm{A} \rightarrow \mathrm{B})$, nilai confidence dapat diperoleh dengan rumus berikut :

$$
\text { Confidence }=\mathrm{P}(\mathrm{B} \mid \mathrm{A})=\frac{\sum \text { Transaksi A dan } \mathrm{B}}{\sum \text { Transaksi } \mathrm{A}}
$$

\section{HASIL DAN PEMBAHASAN}

Pada tahap ini menjelaskan mengenai alur sistem, kebutuhan aktor dan kebutuhan fungsional, dan menjelaskan implementasi.

\subsection{Alur Sistem}

Pada bagian ini menjelaskan alur sistem customer relationship management (CRM) dapat dilihat pada gambar activity diagram berikut :

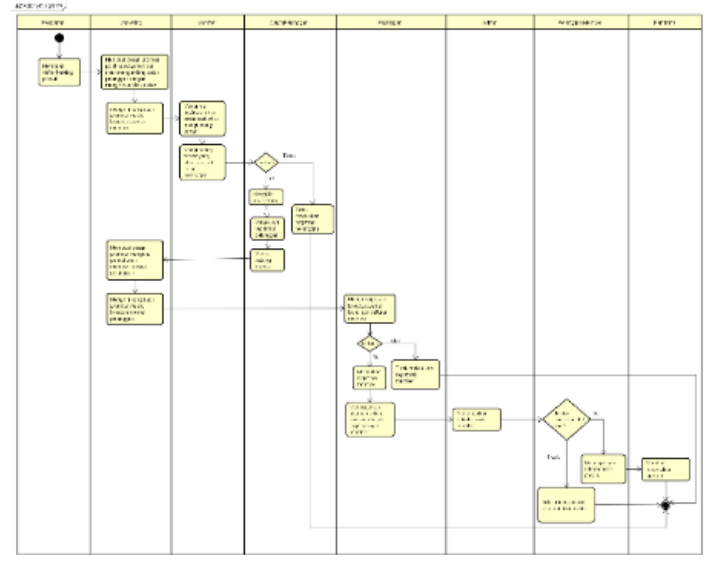

\section{Gambar 1. Alur Sistem CRM}

Pelayanan membuat daftar katalog produk pada system, marketing membuat dan mengirimkan melalui broadcast email member isi pesan tersebut yaitu promosi point kepada member jika member ingin mendapatkan point tersebut maka harus mengundang teman lain sebagai calon pelanggan, calon pelanggan yang tertarik dengan promosi tersebut maka akan mengklik link sistem dan melakukan registrasi pelanggan serta dapat melihat katalog produk, jika calon pelanggan tidak tertarik maka tidak melakukan registrasi pelanggan.

Marketing membuat pesan dan mengirimkan broadcast email kepada pelanggan mengenai pendaftaran member. Pelanggan menerima notifikasi broadcast email dari marketing, jika pelanggan tertarik maka akan melakukan registrasi member, jika tidak maka pelanggan tidak melakukan registrasi member. Pelanggan yang sudah melakukan registrasi member akan mendapatkan username dan password untuk login sebagai member.

Admin menginputkan data transaksi member, jika data transaksi member melebihi dari lima kali transaksi maka member tersebut akan mendapatkan rekomendasi produk melalui system perhitungan tersebut menggunakan metode asosiasi algoritma apriori, jika jumlah transaksi member kurang dari lima maka tidak mendapatkan rekomendasi produk.

Manajer membuat rekapitulasi laporan pelanggan, laporan member, laporan event, dan laporan kepuasan pelanggan setiap bulannya.

\subsection{Kebutuhan Aktor dan Kebutuhan Fungsional}

Sesuai dengan penjelasan alur sistem maka pada bagian ini menjelaskan aktor yang 
terlibat di dalam sistem dan penjelasan fungsifungsi yang ada di dalam sistem.

Tabel 1. Kebutuhan Aktor dan Kebutuhan Fungsional

\begin{tabular}{|c|c|c|}
\hline No & Aktor & Kebutuhan Fungsional \\
\hline 1. & Admin & $\begin{array}{l}\text { Kelola } \text { user, kelola } \\
\text { transaksi, kelola member, } \\
\text { kelola pelanggan }\end{array}$ \\
\hline 2. & Marketing & $\begin{array}{l}\text { Kelola promosi, kelola } \\
\text { broadcast }\end{array}$ \\
\hline 3. & Pelayanan & $\begin{array}{l}\text { Kelola katalog, kelola faq, } \\
\text { kelola kuesioner, kelola } \\
\text { event }\end{array}$ \\
\hline 4. & $\begin{array}{l}\text { Calon } \\
\text { Pelanggan }\end{array}$ & Registrasi Pelanggan \\
\hline 5. & Pelanggan & $\begin{array}{l}\text { Melihat detail katalog dan } \\
\text { melakukan }\end{array}$ \\
\hline 6. & $\begin{array}{l}\text { Pelanggan } \\
\text { Member }\end{array}$ & $\begin{array}{l}\text { Melihat faq, lihat detail } \\
\text { katalog, lihat jadwal } \text { event, } \\
\text { lihat point, isi penilaian, } \\
\text { kelola keluhan }\end{array}$ \\
\hline 7. & Manajer & $\begin{array}{l}\text { Merekapitulasi laporan } \\
\text { pelanggan, laporan } \\
\text { member, laporan event, } \\
\text { dan laporan kepuasan } \\
\text { pelanggan }\end{array}$ \\
\hline
\end{tabular}

Kebutuhan pengguna fungsional di dalam sebuah sistem disebut dengan kebutuhan fungsional . Kebutuhan fungsional dapat dilihat pada gambar use case diagram berikut.

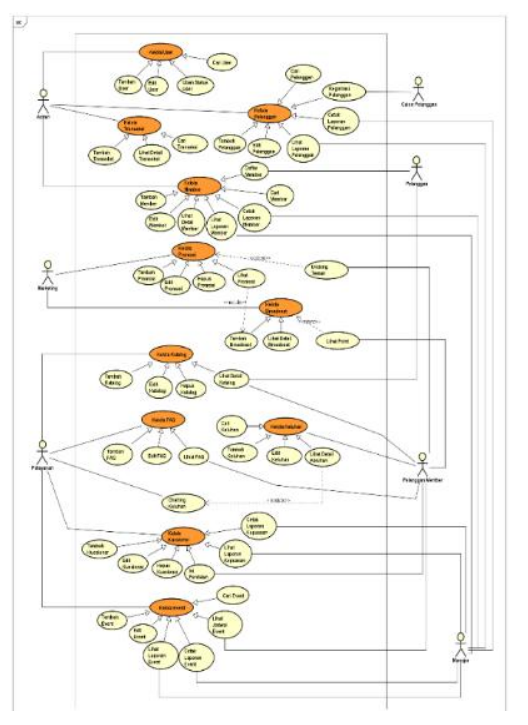

Gambar 2. Use Case Diagram

\subsection{Implementasi}

Tahap implementasi merupakan tahap untuk menjelaskan implementasi dari tahap analisa kebutuhan yang sudah dilakukan. Dimana di dalam pengimplementasiannya penelitian ini menggunakan framework CodeIgniter (CI) untuk membuat tampilan website, database MySql.

a. Antarmuka Kelola Transaksi

Antarmuka kelola transaksi digunakan oleh aktor admin untuk mengelola data transaksi baru pada sistem. Kelola transaksi ini dapat menentuka rekomendasi produk berdasarkan histori transaksi pelanggan member.

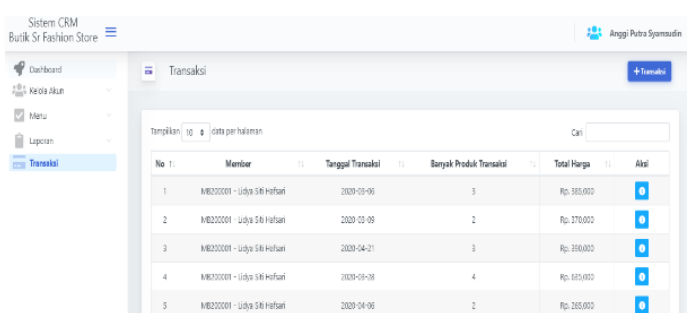

Gambar 3. Antarmuka Kelola Transaksi

b. Antarmuka Form Tambah Transaksi

Antarmuka form tambah transaksi digunakan untuk menginputkan data transaksi pelanggan member pada sistem.

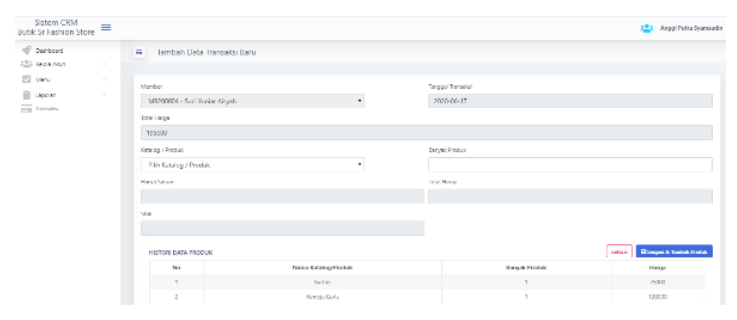

Gambar 4. Antarmuka Form Tambah Transaksi

c. Antarmuka Halaman Rekomendasi Produk Antarmuka halaman rekomendasi produk berdasarkan histori transaksi member dikirim broadcast melalui email member.

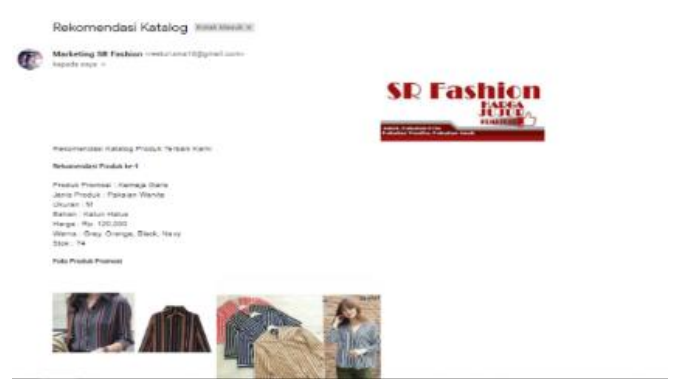

Gambar 5. Antarmuka Halaman Rekomendasi Produk 


\section{PENGUJIAN}

Kebutuhan fungsional dari suatu sistem menjadi tujuan pengujian, agar dapat membuktikan jika kebutuhan fungsional tersebut hasilnya sesuai dengan requirement yang sudah dibuat. Pada penelitian ini pengujian dilakukan dengan uji Black Box, User Acceptance Test (UAT), dan pengujian White Box.

\subsection{Metode Asosiasi Algoritma Apriori}

Terdapat 22 produk yang dijual di Butik SR Fashion Store ini. Namun untuk perhitungan pada penelitian ini mengambil 5 sample produk dan 7 jumlah transaksi dari satu member. Data produk dan data transaksi dapat dilihat pada Tabel 1 dan Tabel 2.

Tabel 2. Data Produk

\begin{tabular}{cc}
\hline No & Nama Produk \\
\hline 1. & Gamis \\
2. & Jumpsuit \\
3. & Kemeja \\
4. & Jaket \\
5. & Celana \\
\hline
\end{tabular}

Tabel 3. Data Transaksi

\begin{tabular}{cc}
\hline Transaksi & Item \\
\hline 1. & Jaket, Celana, Kemeja \\
2. & Kemeja, Gamis \\
3. & Kemeja, Jumpsuit, Jaket \\
4. & Gamis, Kemeja, Celana, \\
& Jaket \\
5. & Celana, Jaket \\
6. & Celana, Kemeja, Jumpsuit \\
7. & Jumpsuit, Jaket, Gamis \\
\hline
\end{tabular}

Selanjutnya melakukan langkah-langkah perhitungan untuk menentukan nilai support dan confidence yang didapat. Berikut langkahlangkah perhitungannya :

a. Pisahkan masing-masing item yang dibeli berdasarkan tabel transaksi diatas, data item yang dibeli dapat dilihat pada Tabel 4.

Tabel 4. Data Item yang Dibeli

\begin{tabular}{cc}
\hline No & Item \\
\hline 1. & Gamis \\
2. & Jumpsuit \\
3. & Kemeja \\
4. & Jaket \\
5. & Celana
\end{tabular}

b. Buat tabel dan hitung jumlah dari masingmasing item yang dibeli berdasarkan tabel transaksi diatas, dapat dilihat pada Tabel 5.

Tabel 5. Perhitungan Jumlah Item

\begin{tabular}{cccccc}
\hline No & $\begin{array}{c}\text { Ga } \\
\text { mis }\end{array}$ & $\begin{array}{c}\text { Jump } \\
\text { suit }\end{array}$ & $\begin{array}{c}\text { Kem } \\
\text { eja }\end{array}$ & Jaket & $\begin{array}{c}\text { Cel } \\
\text { ana }\end{array}$ \\
\hline 1. & 0 & 0 & 1 & 1 & 1 \\
2. & 1 & 0 & 1 & 0 & 0 \\
3. & 0 & 1 & 1 & 1 & 0 \\
4. & 1 & 0 & 1 & 1 & 1 \\
5. & 0 & 0 & 0 & 1 & 1 \\
6. & 0 & 1 & 1 & 0 & 1 \\
7. & 1 & 1 & 0 & 1 & 0 \\
\hline
\end{tabular}

c. Menentukan frekuensi yaitu $(Q)=3$. Dari tabel diatas total $Q$ untuk transaksi $\mathrm{k}=1$ (1 unsur), semuanya lebih besar dari $\bullet$. Maka $\mathrm{F} 1=\{$ Gamis $\},\{$ Jumpsuit $\},\{$ Kemeja $\}$, \{Jaket\}, \{Celana\}. Untuk $\mathrm{k}=2$ (2 unsur) maka dapat diperoleh himpunan $\mathrm{F} 2=$ \{\{Gamis, Jumpsuit\}, \{Gamis, Kemeja\}, \{Gamis, Jaket\}, \{Gamis, Celana\}, \{Jumpsuit, Kemeja\}, \{Jumpsuit, Jaket\}, \{Jumpsuit, Celana\}, \{Kemeja, Jaket\}, $\{$ Kemeja, Celana $\},\{$ Jaket, Celana $\}$.

d. Buat tabel dari masing-masing unsur yang ada pada F2, dapat dilihat pada tabel-tabel berikut.

\begin{tabular}{cccc}
\hline T & Gamis & Jumpsuit & F \\
\hline 1 & 0 & 0 & $\mathrm{~S}$ \\
2 & 1 & 1 & $\mathrm{~S}$ \\
3 & 0 & 1 & $\mathrm{~S}$ \\
4 & 1 & 1 & $\mathrm{~S}$ \\
5 & 0 & 0 & $\mathrm{~S}$ \\
6 & 0 & 1 & $\mathrm{~S}$ \\
7 & 1 & 1 & $\mathrm{P}$ \\
& & $\sum=$ & 1 \\
\hline T & Gamis & Kemeja & $\mathbf{F}$ \\
\hline 1 & 0 & 1 & $\mathrm{~S}$ \\
2 & 1 & 1 & $\mathrm{P}$ \\
3 & 0 & 1 & $\mathrm{~S}$ \\
4 & 1 & 1 & $\mathrm{P}$ \\
5 & 0 & 0 & $\mathrm{~S}$ \\
6 & 0 & 1 & $\mathrm{~S}$ \\
7 & 1 & 0 & $\mathrm{~S}$ \\
& & $\sum=$ & 2 \\
\hline & & & \\
\hline T & Gamis & Jaket & $\mathbf{F}$ \\
\hline 1 & 0 & 1 & $\mathrm{~S}$ \\
2 & 1 & 0 & $\mathrm{~S}$ \\
3 & 0 & 1 & $\mathrm{~S}$ \\
4 & 1 & 1 & $\mathrm{P}$ \\
5 & 0 & 1 & $\mathrm{~S}$
\end{tabular}




\begin{tabular}{|c|c|c|c|}
\hline \multirow{3}{*}{$\begin{array}{l}6 \\
7\end{array}$} & 0 & 0 & S \\
\hline & 1 & 1 & $\mathrm{P}$ \\
\hline & & $\sum=$ & 2 \\
\hline $\mathbf{T}$ & Gamis & Celana & $\mathbf{F}$ \\
\hline 1 & 0 & 1 & $\mathrm{~S}$ \\
\hline 2 & 1 & 0 & $\mathrm{~S}$ \\
\hline 3 & 0 & 0 & $S$ \\
\hline 4 & 1 & 1 & $\mathrm{P}$ \\
\hline 5 & 0 & 1 & $S$ \\
\hline 6 & 0 & 1 & S \\
\hline 7 & 1 & 0 & S \\
\hline & & $\sum=$ & 1 \\
\hline $\mathbf{T}$ & Jumpsuit & Kemeja & $\mathbf{F}$ \\
\hline 1 & 0 & 1 & $\mathrm{~S}$ \\
\hline 2 & 0 & 1 & S \\
\hline 3 & 1 & 1 & $\mathrm{P}$ \\
\hline 4 & 0 & 1 & $S$ \\
\hline 5 & 0 & 0 & $\mathrm{~S}$ \\
\hline 6 & 1 & 1 & $\mathrm{P}$ \\
\hline 7 & 1 & 0 & $\mathrm{~S}$ \\
\hline & & $\sum=$ & 2 \\
\hline $\mathbf{T}$ & Jumpsuit & Jaket & $\mathbf{F}$ \\
\hline 1 & 0 & 1 & $\mathrm{~S}$ \\
\hline 2 & 0 & 0 & S \\
\hline 3 & 1 & 1 & $\mathrm{P}$ \\
\hline 4 & 0 & 1 & S \\
\hline 5 & 0 & 1 & S \\
\hline 6 & 1 & 0 & S \\
\hline 7 & 1 & 1 & $\mathrm{P}$ \\
\hline & & $\sum=$ & 1 \\
\hline
\end{tabular}

\begin{tabular}{cccc}
\hline T & Jumpsuit & Celana & F \\
\hline 1 & 0 & 1 & $\mathrm{~S}$ \\
2 & 0 & 0 & $\mathrm{~S}$ \\
3 & 1 & 0 & $\mathrm{~S}$ \\
4 & 0 & 1 & $\mathrm{~S}$ \\
5 & 0 & 1 & $\mathrm{~S}$ \\
6 & 1 & 1 & $\mathrm{P}$ \\
7 & 1 & 0 & $\mathrm{~S}$ \\
& & $\sum=$ & 1 \\
\hline
\end{tabular}

\begin{tabular}{cccc}
\hline T & Kemeja & Jaket & F \\
\hline 1 & 1 & 1 & $\mathrm{P}$ \\
2 & 1 & 0 & $\mathrm{~S}$ \\
3 & 1 & 1 & $\mathrm{P}$ \\
4 & 1 & 1 & $\mathrm{P}$ \\
5 & 0 & 1 & $\mathrm{~S}$ \\
6 & 1 & 0 & $\mathrm{~S}$ \\
7 & 0 & 1 & $\mathrm{~S}$ \\
& & $\sum=$ & 3 \\
\hline
\end{tabular}

\begin{tabular}{llll} 
& & & \\
\hline T & Kemeja & Celana & F \\
\hline
\end{tabular}

\begin{tabular}{cccc}
\hline 1 & 1 & 1 & $\mathrm{P}$ \\
2 & 1 & 0 & $\mathrm{~S}$ \\
3 & 1 & 0 & $\mathrm{~S}$ \\
4 & 1 & 1 & $\mathrm{P}$ \\
5 & 0 & 1 & $\mathrm{~S}$ \\
6 & 1 & 1 & $\mathrm{P}$ \\
7 & 0 & 0 & $\mathrm{~S}$ \\
& & $\sum=$ & 3 \\
\hline & & & \\
\hline $\mathbf{T}$ & Jaket & Celana & $\mathbf{F}$ \\
\hline 1 & 1 & 1 & $\mathrm{P}$ \\
2 & 0 & 0 & $\mathrm{~S}$ \\
3 & 1 & 0 & $\mathrm{~S}$ \\
4 & 1 & 1 & $\mathrm{P}$ \\
5 & 1 & 1 & $\mathrm{P}$ \\
6 & 0 & 1 & $\mathrm{~S}$ \\
7 & 1 & 0 & $\mathrm{~S}$ \\
& & $\sum=$ & 3 \\
\hline
\end{tabular}

Dari tabel 2 unsur diatas, $\mathrm{P}$ artinya item yang dijual bersamaan, $S$ artinya tidak adaa item yang dijual atau tidak ada transaksi, sedangkan $\sum$ melambangkan jumlah frekuensi item set. Jumlah frekuensi item set $\left(\sum>=Q\right)$. Dari tabel diatas maka didapat F2 $=\{\{$ Kemeja, Jaket $\},\{$ Kemeja, Celana $\},\{$ Jaket, Celana $\}$.

Kombinasi dari 2 item set dalam F2, dapat kita gabung menjadi calon 3 item set. Item set yang dapat digabungkan adalah item set yang memiliki kesamaan dalam $\mathrm{k}=1$ item pertama untuk $\mathrm{k}=3$ ( 3 unsur), himpunan yang mungkin terbentuk adalah $\{$ Kemeja, Jaket, Celana $\}$.

a. Buat tabel berdasarkan unsur F3, dapat dilihat pada Tabel V.

\begin{tabular}{ccccc}
\hline T & Kemeja & Jaket & Celana & F \\
\hline 1 & 1 & 1 & 1 & $\mathrm{P}$ \\
2 & 1 & 0 & 0 & $\mathrm{~S}$ \\
3 & 1 & 1 & 0 & $\mathrm{~S}$ \\
4 & 1 & 1 & 1 & $\mathrm{P}$ \\
5 & 0 & 1 & 1 & $\mathrm{~S}$ \\
6 & 1 & 0 & 1 & $\mathrm{~S}$ \\
7 & 0 & 1 & 0 & $\mathrm{~S}$ \\
& & & $\sum=$ & 2 \\
\hline
\end{tabular}

Dari tabel tersebut didapat $\mathrm{F} 3=\{\}$, karena tidak ada $\sum>=Q$ sehingga F4, F5, F6, dan F7 juga merupakan himpunan kosong.

b. Menentukan Antecedenct dan Consequent. Tentukan (ss-s) sebagai antecedent dan $\mathbf{s}$ sebagai concequent dari Fk yang telah didapat. Pada F2 didapat himpunan 
$\{\{$ Kemeja, Jaket $\}, \quad\{$ Kemeja, Celana $\}$, \{Jaket, Celana $\}$. Maka dapat disusun :

a) Untuk \{Kemeja, Jaket $\}$

- Jika (ss-s) = kemeja, jika $\mathrm{s}=$ jaket maka $\rightarrow$ if buy kemeja then buy jaket

- Jika (ss-s) $=$ jaket, jika $\mathrm{s}=$ kemeja maka $\rightarrow$ if buy jaket then buy kemeja

b) Untuk $\{$ Kemeja, Celana $\}$

- Jika (ss-s) = kemeja, jika $\mathrm{s}=$ celana maka $\rightarrow$ if buy kemeja then buy celana

- Jika (ss-s) = celana, jika $\mathrm{s}=$ kemeja maka $\rightarrow$ if buy celana then buy kemeja

c) Untuk \{Jaket, Celana $\}$

- Jika (ss-s) = jaket, jika $\mathrm{s}=$ celana maka $\rightarrow$ if buy jaket then buy celana

- Jika (ss-s) = celana, jika $\mathrm{s}=$ jaket maka $\rightarrow$ if buy celana then buy jaket

c. Menentukan rule, dari langkah diatas rule yang kita dapatkan yaitu sebanyak 6 rule yaitu:

a) if buy kemeja then buy jaket

b) if buy jaket then buy kemeja

c) if buy kemeja then buy celana

d) if buy celana then buy kemeja

e) if buy jaket then buy celana

f) if buy celana then buy jaket

d. Menghitung nilai Support dan Confidence menggunakan rumus sebagai berikut :

Support $=\sum$ item yang dibeli sekaligus $\times 100 \%$ Ejumlah seluruh transaksi

Confidence $=\sum$ item yang dibeli sekaligus $\mathrm{x} 100 \%$ $\sum$ jumlah transaksi pada bagian antecedent

Sehingga didapat tabel sebagai berikut :

Tabel 6. Hasil Nilai Support dan Confidence

\begin{tabular}{|c|c|c|c|}
\hline $\begin{array}{l}\text { If antecedent then } \\
\text { consequent }\end{array}$ & Support & & Confidence \\
\hline if buy kemeja then & $(3 / 7)$ & $\mathrm{x}$ & $(3 / 5) \times 100 \%$ \\
\hline & $\begin{array}{l}100 \% \\
42,86\end{array}$ & $=$ & $=60 \%$ \\
\hline jaket then & $(3 / 7)$ & $\mathrm{X}$ & $(3 / 5) \times 100 \%$ \\
\hline buy keme & $\begin{array}{l}100 \% \\
42,86\end{array}$ & $=$ & $=60 \%$ \\
\hline $\begin{array}{l}\text { if buy kemeja then } \\
\text { buy celana }\end{array}$ & $\begin{array}{l}(3 / 7) \\
100 \% \\
42,86\end{array}$ & $\begin{array}{l}\mathrm{x} \\
=\end{array}$ & $\begin{array}{l}(3 / 5) \times 100 \% \\
=60 \%\end{array}$ \\
\hline
\end{tabular}

\begin{tabular}{lllll}
\hline if buy celana then & $(3 / 7)$ & $\mathrm{x}$ & $(3 / 4) \times 100 \%$ \\
buy kemeja & $100 \%$ & $=75 \%$ & \\
& 42,86 & & & \\
if buy jaket then & $(3 / 7)$ & $\mathrm{x}$ & $(3 / 5) \times$ & $100 \%$ \\
buy celana & $100 \%$ & $=$ & $=60 \%$ & \\
& 42,86 & & & \\
if buy celana then & $(3 / 7)$ & $\mathrm{x}$ & $(3 / 4) \times$ & $100 \%$ \\
buy jaket & $100 \%$ & $=$ & $=75 \%$ & \\
& 42,86 & &
\end{tabular}

e. Mengkalikan hasil nilai support dan confidence. Setelah didapat support dan confidence untuk masing-masing kandidat, lakukan perkalian antar support dan confidence, dimana confidence diambil dari $70 \%$ keatas. Sehingga dapat diperoleh tabel :

Tabel 7. Hasil Perkalian Nilai Support dan Confidence

\begin{tabular}{llll}
\hline $\begin{array}{l}\text { If actecedent } \\
\text { then } \\
\text { concequent }\end{array}$ & Support & $\begin{array}{l}\text { Confiden } \\
\text { ce }\end{array}$ & S x C \\
\hline $\begin{array}{l}\text { If buy celana } \\
\text { then buy }\end{array}$ & $42 ., 86 \%$ & $75 \%$ & 0,3214 \\
$\begin{array}{l}\text { kemeja } \\
\text { If buy celana }\end{array}$ & $42,86 \%$ & $75 \%$ & 5 \\
then buy jaket & & & 0,3214 \\
\hline
\end{tabular}

f. Setelah didapat hasil perkalian support dan confidence pilihlah yang hasil perkaliannya paling besar. Hasil paling besar dari perkalian tersebut merupakan rule yang dipakai saat menjual. Karena hasil perkalian dari k-2 penjualan diatas bernilai sama, maka semuanya bisa dijadikan rule.

a) Jika membeli celana maka akan membeli kemeja dengan support $42,86 \%$ dan confidence $75 \%$

b) Jika membeli celana maka akan membeli jaket dengan support $42,86 \%$ dan confidence $75 \%$.

\subsection{Black Box Testing}

Black box testing adalah pengujian yang dilakukan hanya mengamati hasil eksekusi melalui data uji dan memeriksa fungsional dari perangkat lunak (Mustaqbal, Firdaus and Rahmadi, 2015). Pengujian menggunakan black box dapat dilihat pada Tabel 8 berikut.

Tabel 8. Pengujian Black Box

\begin{tabular}{cllc}
\hline No & Model Uji & Pengguna & Keberhasilan \\
\hline 1. & $\begin{array}{l}\text { Isi form } \\
\text { login }\end{array}$ & $\begin{array}{l}\text { Seluruh } \\
\text { pengguna }\end{array}$ & $100 \%$ \\
2. & $\begin{array}{l}\text { Mengelola } \\
\text { data } \\
\text { transaksi }\end{array}$ & Admin & $100 \%$ \\
\hline
\end{tabular}




\begin{tabular}{|c|c|c|c|}
\hline & $\begin{array}{l}\text { dan } \\
\text { seluruh } \\
\text { pengguna }\end{array}$ & & \\
\hline 3. & $\begin{array}{l}\text { Mengelola } \\
\text { promosi } \\
\text { dan } \\
\text { broadcast }\end{array}$ & Marketing & $100 \%$ \\
\hline 4. & $\begin{array}{l}\text { Mengelola } \\
\text { data } \\
\text { katalog, } \\
\text { kuesioner, } \\
\text { faq, dan } \\
\text { event }\end{array}$ & Pelayanan & $100 \%$ \\
\hline 5. & $\begin{array}{l}\text { Melakukan } \\
\text { registrasi } \\
\text { pelanggan }\end{array}$ & $\begin{array}{l}\text { Calon } \\
\text { Pelanggan }\end{array}$ & $100 \%$ \\
\hline 6. & $\begin{array}{l}\text { Melakukan } \\
\text { registrasi } \\
\text { member }\end{array}$ & Pelanggan & $100 \%$ \\
\hline 7. & $\begin{array}{l}\text { Mengelola } \\
\text { Keluhan }\end{array}$ & $\begin{array}{l}\text { Pelanggan } \\
\text { Member }\end{array}$ & $100 \%$ \\
\hline
\end{tabular}

\subsection{Pengujian User Acceptance Test (UAT)}

User Acceptance Test (UAT) adalah suatu proses pengujian yang dilakukan oleh pengguna dengan hasil output sebuah dokumen hasil uji yang dapat dijadikan bukti bahwa software sudah diterima dan sudah memenuhi kebutuhan yang diminta. Berikut langkahlangkah mengerjakan pengujian UAT. Disini penulis mengambil sample kuesioner yang diberikan kepada pelanggan.

a. Menentukan Jawaban dan Nilai Bobot

Pada tahap ini kita menentukan pilihan jawaban serta nilai bobot yang akan digunakan untuk pengisian kuesioner.

Tabel 9. Pilihan Jawaban dan Nilai Bobot

\begin{tabular}{lc}
\hline \multicolumn{1}{c}{ Pilihan Jawaban } & Nilai Bobot \\
\hline A : Sangat & 5 \\
Mudah/Bagus/Sesuai/Jelas & \\
B : Mudah/Bagus/Sesuai/Jelas & 4 \\
C : Netral & 3 \\
D : Cukup & 2 \\
E : Sangat Sulit/Jelek/Tidak & 1 \\
Sesuai/Tidak Jelas & \\
\hline
\end{tabular}

b. Pelanggan

Pada pengujian UAT ini user pelanggan pada sistem menguji hak aksesnya seperti melakukan login, melihat daftar produk dan promosi pada katalog, dan melakukan pendaftaran member.
Tabel 10. Kuesioner Pelanggan

\begin{tabular}{|c|c|c|}
\hline No & Pertanyaan & $\begin{array}{llllll} & A & \text { B } & \text { C } & \text { D } & \text { E } \\
\end{array}$ \\
\hline 1. & $\begin{array}{l}\text { Apakah halaman utama } \\
\text { sistem membantu anda } \\
\text { menemukan informasi } \\
\text { promosi? }\end{array}$ & \\
\hline 2. & $\begin{array}{l}\text { Apakah tampilan login } \\
\text { sangat menarik? }\end{array}$ & \\
\hline 3. & $\begin{array}{l}\text { Apakah anda merasa } \\
\text { kesulitan untuk } \\
\text { melakukan login sebagai } \\
\text { pelanggan baru? }\end{array}$ & \\
\hline 4. & $\begin{array}{l}\text { Apakah tampilan sistem } \\
\text { sebagai pelanggan sangat } \\
\text { menarik? }\end{array}$ & \\
\hline 5. & $\begin{array}{l}\text { Apakah menu yang ada } \\
\text { di dalam sistem sesuai } \\
\text { dengan hak akses anda? }\end{array}$ & \\
\hline 6. & $\begin{array}{l}\text { Apakah menu katalog } \\
\text { membantu anda } \\
\text { menemukan informasi } \\
\text { produk dan promosi? }\end{array}$ & \\
\hline 7. & $\begin{array}{l}\text { Apakah anda merasa } \\
\text { kesulitan saat melakukan } \\
\text { pendaftaran sebagai } \\
\text { member? }\end{array}$ & \\
\hline 8. & $\begin{array}{l}\text { Apakah anda menerima } \\
\text { notifikasi pesan hak akses } \\
\text { sebagai member pada } \\
\text { email dengan cepat? }\end{array}$ & \\
\hline
\end{tabular}

Tabel 11. Hasil Kuesioner Pelanggan

\begin{tabular}{ccccccccccc}
\hline N & \multicolumn{4}{c}{ Jawaban } & \multicolumn{4}{c}{ Presentase } \\
o & A & B & C & D & E & A & B & C & D & E \\
\hline 1. & 4 & 1 & 0 & 0 & 0 & $8 \%$ & $2 \%$ & 0 & 0 & 0 \\
2. & 2 & 3 & 0 & 0 & 0 & $4 \%$ & $6 \%$ & 0 & 0 & 0 \\
3. & 4 & 1 & 0 & 0 & 0 & $8 \%$ & $2 \%$ & 0 & 0 & 0 \\
4. & 2 & 3 & 0 & 0 & 0 & $4 \%$ & $6 \%$ & 0 & 0 & 0 \\
5. & 3 & 2 & 0 & 0 & 0 & $6 \%$ & $4 \%$ & 0 & 0 & 0 \\
6. & 2 & 3 & 0 & 0 & 0 & $4 \%$ & $6 \%$ & 0 & 0 & 0 \\
7. & 4 & 1 & 0 & 0 & 0 & $8 \%$ & $2 \%$ & 0 & 0 & 0 \\
8. & 2 & 2 & 1 & 0 & 0 & $4 \%$ & $4 \%$ & $2 \%$ & 0 & 0 \\
\hline
\end{tabular}

Jawaban kuesioner user pelanggan diperoleh berdasarkan jumlah responden yang menjawab masing-masing pilihan jawaban. Jika nilai presentase diperoleh berdasarkan hasil hitungan melalui dua tahap yaitu :
a. Total Bobot
Jumlah Responden
b. Jumlah Perhitungan $\mathrm{x} 100 \%$ Nilai Bobot


Tabel 12. Hasil Kuesioner Pelanggan

\begin{tabular}{|c|c|c|c|c|c|c|c|c|c|}
\hline No & Pertanyaan & Ax5 & Bx4 & $\mathrm{C} \times 3$ & Dx2 & Ex1 & Jumlah & $\begin{array}{c}\text { Rata- } \\
\text { rata }\end{array}$ & Presentase \\
\hline 1. & $\begin{array}{l}\text { Apakah halaman utama } \\
\text { sistem membantu anda } \\
\text { menemukan informasi } \\
\text { promosi? }\end{array}$ & 20 & 4 & 0 & 0 & 0 & 24 & 4.8 & $4.8 \%$ \\
\hline 2. & $\begin{array}{l}\text { Apakah tampilan login } \\
\text { sangat menarik? }\end{array}$ & 10 & 12 & 0 & 0 & 0 & 22 & 4.4 & $2.2 \%$ \\
\hline 3. & $\begin{array}{l}\text { Apakah anda merasa } \\
\text { kesulitan untuk } \\
\text { melakukan login scbagai } \\
\text { pelanggan baru? }\end{array}$ & 20 & 4 & 0 & 0 & 0 & 24 & 4.8 & $2.4 \%$ \\
\hline 4. & $\begin{array}{l}\text { Apakah tampilan sistem } \\
\text { sebagai pelanggan sangat } \\
\text { menarik? }\end{array}$ & 10 & 12 & 0 & 0 & 0 & 22 & 4.4 & $2.2 \%$ \\
\hline 5. & $\begin{array}{l}\text { Apakah menu yang ada } \\
\text { di dalam sistem sesuai } \\
\text { decran havakssand? }\end{array}$ & 15 & 8 & 0 & 0 & 0 & 23 & 4.6 & $2.3 \%$ \\
\hline 6. & $\begin{array}{l}\text { Apakah menu katalog } \\
\text { membantu anda } \\
\text { menemukan informasi } \\
\text { produk dan promosi? }\end{array}$ & 10 & 12 & 0 & 0 & 0 & 22 & 4.4 & $2.2 \%$ \\
\hline 7. & $\begin{array}{l}\text { Apakaha anda merasa } \\
\text { kesultan saat melakukan } \\
\text { pendaftaran sebagai } \\
\text { member? }\end{array}$ & 20 & 4 & 0 & 0 & 0 & 24 & 4.8 & $2.4 \%$ \\
\hline 8. & $\begin{array}{l}\text { Apakah anda menerima } \\
\text { notifikasi pesan hak } \\
\text { akses sebagai member } \\
\text { pada email dengan } \\
\text { cepat? }\end{array}$ & 10 & 8 & 3 & 0 & 0 & 21 & 4.2 & $1.4 \%$ \\
\hline
\end{tabular}

Dari tabel diatas dapat dilihat bahwa jumlah nilai dari 5 responden untuk pertanyaan pertama adalah 24. Nilai rata-ratanya adalah 4.8 , dan nilai presentase pertanyaan pertama yaitu $4.8 \%$. Perhitungan tersebut dapat diperoleh menggunakan rumus :

a. Menghitung Rata-Rata

Rata-rata $=$ Jumlah Penelitian Jumlah Responden

b. Menghitung Presentase

Presentase $=$ Hasil Rata-Rata $\times 100 \%$ Jumlah nilai yang diisi

\section{KESIMPULAN}

Berdasarkan hasil penelitian diatas menunjukan bahwa Sistem Customer Relationship Management (CRM) menggunakan Metode Asosiasi Algoritma Apriori dapat membantu meningkatkan kualitas pelayanan dengan memberikan rekomendasi produk kepada pelanggan dengan dibuktikannya berdasarkan hasil perhitungan metode asosiasi menggunakan algoritma apriori menghasilkan dua rule dengan nilai support $42,86 \%$ dan nilai confidence $75 \%$. Serta berdasarkan pengujian menggunakan black box menghasilkan $100 \%$ keberhasilan pengujian terhadap kebutuhan fungsional sistem. Berdasarkn pengujian UAT yang telah dilakukan menggunakan kuesioner menghasilkan nilai kepuasan pada sistem yang dibangun. Hasil dari kedua pengujian tersebut lebih baik dibandingkan dengan memberikan rekomendasi kepada pelanggan secara langsung yang mengakibatkan ketidak nyamanan atas pemberian pelayanan kepada pelanggan jika rekomendasi yang diberikan tidak sesuai dengan keinginan dan kriteria pelanggan.

\section{DAFTAR PUSTAKA}

Denniswara, E. P. (2018) 'Pengaruh Kualitas Produk, harga dan Promosi terhadap Intensi membeli ulang produk My Idea', Strategi Segmentasi Pasar Dan Promosi Dalam Meningkatkan Volume Penjualan, 1, p. 10.

Faisal, Wina, A. (2017) 'Pembangunan Sistem Customer Relationship Management Pada PT. Central Georgette Nusantara', Teknik Informatika, pp. 431-438.

Fatoni, C. S., Utami, E. and Wibowo, F. W. (2018) 'Sistem Rekomendasi Produk Online Store Menggunakan Metode Apriori', Jurnal INFORMA Politeknik Indonusa Surakarta, 4(2), pp. 20-27.

Listriani, D., Setyaningrum, A. H. and Eka, F. (2018) 'Penerapan Metode Asosiasi menggunakan Algoritma Apriori pada Aplikasi Analisa Pola Belanja Konsumen (Studi Kasus Toko Buku Gramedia Bintaro)', Jurnal Teknik Informatika, 9(2), pp. 120-127. doi: 10.15408/jti.v9i2.5602.

Mustaqbal, M. S., Firdaus, R. F. and Rahmadi, H. (2015) 'Pengujian Aplikasi menggunakan Black Box Testing Boundary Value Analysis (Studi Kasus : Aplikasi Prediksi Kelulusan SNMPTN)', Teknologi Informasi, I(3), pp. 31-36.

Nawawi, Y. (2019) 'Implementasi Data Mining menentukan Rekomendasi Penempatan Buku berdasarkan Pola Peminjaman dengan menggunakan Association Rule', Informatika, 8(5), p. 55.

Soltani, Z. and Navimipour, N. J. (2016) 'Customer relationship management mechanisms: A systematic review of the state of the art literature and recommendations for future research', Computers in Human Behavior, 61, pp. 667-688. doi: 10.1016/j.chb.2016.03.008.

Sophia, D. and Yuniar, L. (2017) 'Implementasi Metode Aturan Asosiasi Menggunakan Algoritma Apriori Pada Data Transaksi Penjualan Di Waroeng Spesial Sambal', Jurnal Informatika dan Komputer, 22(1), pp. $44-56$.

Wijaya, K. N. (2017) 'Analisa Pola Frekuensi Keranjang Belanja dengan Algoritma Apriori', Computer Science, 3(1), pp. 912. 